\section{A KARAOKE APPROACH FOR LANGUAGE TEACHING: THE CASE OF THE "LEARNING TO READ THAI FROM SONGS" PROJECT $^{1}$}

\section{Yuphaphan Hoonchamlong ${ }^{2}$}

\begin{abstract}
Karaoke is music video with text lyrics on screen. Thus karaoke provides audio, visual, and also textual information at the same time. As a language-teaching material, karaoke can therefore be viewed as a short authentic text, with the sung vocals functioning as an audio reading model accompanied by a corresponding visual context. I will discuss the design and implementation of "Learning to Read Thai from Songs", a web-based, interactive, multimedia, instructional-materials project which makes use of the aforementioned desirable features of "karaoke" to create instructional materials for enhancing the instruction of the Thai writing system and students' Thai script recognition practice by using Thai songs.
\end{abstract}

1 This paper was originally presented at the Southeast Asian Linguistics Society (SEALS) XIV conference in May 2004 and was based on a project funded by Arts and Science Faculty Award of University of Hawai'iManoa in 2003.

2 Ph.D., Assistant Professor, and Head, Thai Language Program, Department of Hawaiian and Indo-Pacific Languages, University of Hawai'i-Manoa.

\section{Introduction}

Video is known to be an effective language teaching aid. This paper explores the features of a special type of video: karaoke, music videos with text lyrics on screen, and how these features can be effectively incorporated into instructional materials for teaching reading skills for Less Commonly Taught Languages that use non-Roman-script, using examples from Thai materials. The paper covers the following topics:

- Problems in teaching non-Roman-script languages

- The importance of reading in L2 learning; the reading process

- The features of karaoke that are relevant to the teaching of Thai reading skills

- The design and implementation of the 'Learning to Read Thai from Songs' project

\section{Problems in teaching non-Roman- script languages}

Assuming that the goal of language instruction is for learners to learn all the skills involved in language use: listening, speaking, reading, and writing, one of the main problems of learning to read in a non-Roman-script language is obviously learning to "decode" the unfamiliar script or orthography of the language, especially at the level of grapheme-phoneme (symbolsound) mapping which is crucial to the word-identification and word-recognition process in reading.

This level of grapheme-phoneme mapping occurs in all three major forms of writing system, depending on the unit that is represented by a grapheme. 
1) In logographic/ideographic writing systems such as Chinese, the whole symbol corresponds to the entire phonological form of the morpheme or word.

2) In Syllabic writing systems such as Devanagari or the Kana characters in Japanese, each symbol corresponds to a syllable in the language.

3) In A lphabetic w riting s ystems such a s English and Thai, each symbol (letter) roughly corresponds to a phoneme.

Alphabetic writing systems can be further classified into two groups:

1) systems where there is a one-to-one relationship of letter to phoneme in every or most of the words, and

2) systems where the relationship of letter to phoneme is not regular.

Thai can be regarded as belonging to the first group since the letter-phoneme mapping is quite systematic, ${ }^{3}$ and English can be considered a member of the latter group, since many English words do not have a one-to-one relationship between letters and phonemes.

With respect to word boundaries, which are generally a unit for word identification in reading, Henderson (1984b: 16) observes that most alphabetic scripts mark word boundaries by a space. However, there are alphabetic languages that lack word spacing, such as, Hebrew and Classical Greek. These languages use other devices to mark word final graphemes. Thai and a number of languages on the mainland of Southeast Asia also belong to this latter group of

3 However, there are some interesting contextual shifts in the representations of consonants and vowels. alphabetic writing systems which do not use spaces to mark word boundaries: "thaileavesnospacesbetweenwords". Instead this languages use other devices to mark word boundaries, which present additional problems in recognizing/identifying words among strings of letters for learners of such languages, in addition to learning to decode an unfamiliar script.

In this paper, I will address specifically the problem of reading Thai script, as an example of an alphabetic, non-Roman script that does not use spaces to mark word/syllable boundaries. I will demonstrate how the features of karaoke make it a good audio-visual aid in teaching reading and other skills in Thai, while providing a positive and fun learning experience for language learners.

\section{Characteristics of Thai script}

In summary, the following are notable characteristics of Thai script: ${ }^{4}$

- alphabetic, with fairly systematic correspondence between letter and sound;

- written from left to right;

- no spaces between words/morphemes;

- vowel symbol(s) in fixed position(s) around the initial consonant/consonant clusters;

- tone markers above the initial consonant(s) representing tones-the value of the tones also depends on the class of the initial consonant.

\footnotetext{
${ }^{4}$ Thai scripts developed from "Grantha", an ancient Brahmi script of South India since 1283 A.D. Grantha is also the source of Khmer (Danvivathana 1987).
} 
The following is an example of a Thai sentence in normal Thai writing, i.e., with no spaces between words or syllables. This sentence consists of 5 morphemes. In this example, the vowels are shown in lighter shade to demonstrate how vowel positions correspond with morpheme/syllable boundaries.

\section{เขาเป็นนักเรียนทุน ${ }^{5}$}

The above sentence can be shown with spaces among morphemes as follows:

\section{เขา เป็น นัก เรียน ทุน}

The vowel forms in the above examples Are: ${ }^{6}$

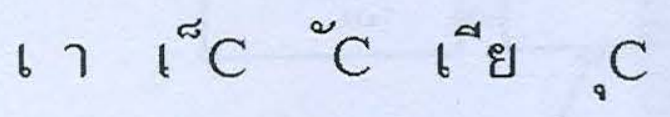

The fixed position of the vowel forms and tone markers in a syllable can be used as a device to help the readers mark/recognize syllable boundaries in Thai writing, especially with vowels placed before initial consonants, which help mark the beginning of a syllable. The fact that most minimum Thai words (morphemes) are monosyllabic means that the vowel positions can be helpful in marking morpheme boundaries as well.

The minimum words in the Thai language are predominantly monosyllabic but polysyllabic words/morphemes also occur. Compounding and reduplicating are two main processes of word formation in Thai (Haas, 1964). Therefore, the syllable is regarded as a unit in Thai that needs to be identified in the reading process (Brown 1979: 30).

\footnotetext{
${ }^{5}$ The sentence means: "He is a scholarship student".

${ }^{6} \mathrm{C}$ stands for a required final consonant.
}

The tasks that a learner of Thai encounters in reading Thai scripts at word level are therefore as follows:

- learn to "decode" or "decipher" unfamiliar scripts, and

- learn to identify syllable, morpheme, and word boundaries.

\section{The importance of reading skill in L2 learning}

Researchers in second language acquisition have found that reading is a powerful language acquisition resource. Many researchers have documented the importance of encouraging authentic reading and writing activities with L2 learners, for example, Tomlinson (2000) and Krashen (1993). However, many L2 learners are inhibited from developing confidence and fluency in reading and miss the opportunity of using reading to acquire L2 because, for them, reading is a negative experience which provides little enjoyment or success (Tomlinson 2000). Therefore, one way of encouraging L2 learners to develop confidence and fluency in reading is to provide positive reading experiences with enjoyment and a certain degree of success.

\section{The reading processes}

Reading is a complex cognitive activity. Research on reading suggests that reading involves two basic cognitive processes (Ehri, 1998):

1) deciphering the symbols (graphemes), and

2) comprehending the meaning of the graphemes and the message conveyed.

"Meaning" here includes word meaning and text meaning. In order to understand 
meaning, a reader makes use of contexts from various sources, such as grammatical and semantic context within the sentence to determine the meaning of the word and situational, pragmatic, and schematic (world knowledge) contexts to understand text.

The two basic levels of cognitive processes above sometimes are referred to as lowerlevel and higher-level processing, with deciphering and word identification as lower-level skills and comprehension of text from various contexts as higher-level skill.

The following (figure 1) summarizes the processes of reading according to the interactive model of reading proposed by Rumelhart (1977) and subsequently as adapted by Ehri (1998: 6).

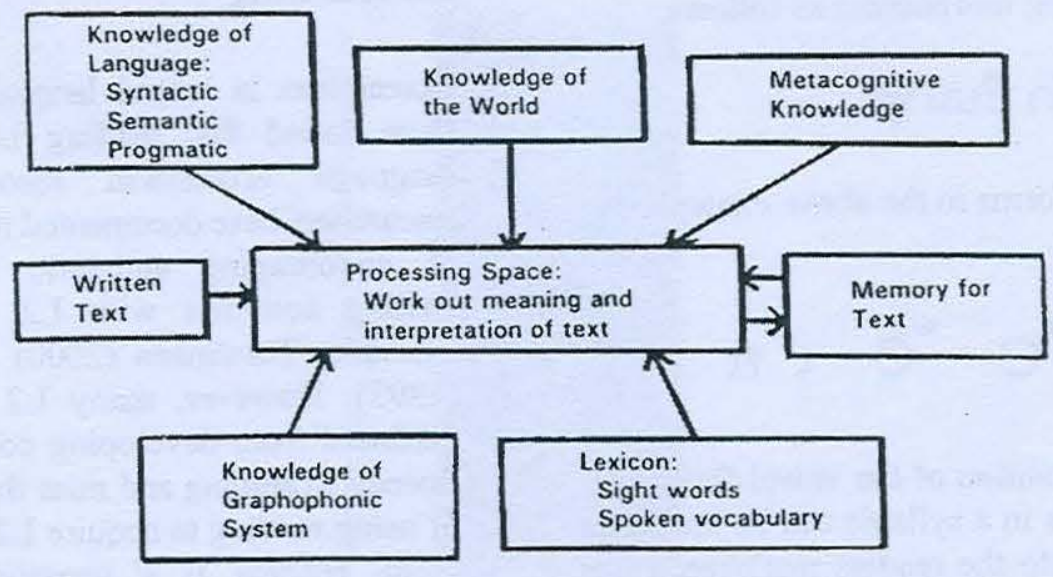

Figure1. Interactive model of reading

The bottom two boxes in the diagram refer to the "lower-levels" of the reading processes.

- The knowledge of the graphophonic system enables a reader to convert letters into sounds in order to decode unfamiliar words.

- The lexicon, or lexical knowledge, refers to words that a reader holds in memory, including the written forms of the words known by sight (Ehri, 1998).

Research on reading shows that readers use various strategies in recognizing words. Ehri (1998) identifies at least 5 different ways.
1) By assembling letters into a blend of sounds: This is a strategy that readers use to read words they have never seen before. This strategy works well with a language with systematic correspondences between letters and sounds.

2) By pronouncing and blending familiar spelling patterns, i.e., by decoding chunks or clusters of letters: This is how a more proficient reader processes longer and less familiar words. The clusters of letters usually correspond to syllables or onsets and rimes of syllables. Syllabic units are not recognized prior to letters, nor vice versa. Both are recognized more or less simultaneously (Weaver 1994: 210). 
3) By retrieving sight word from memory: Readers use this strategy to recognize words that cannot be read accurately by decoding letters into sounds because of idiosyncratic spellings. Proficient readers also automatically recognize many words on sight (Stanovich 1991, cited in Weaver 1994: 210).

4) By analogizing to words already known by sight: Goswami (1990), cited in Ehri (1998) and in Goswami (1998), found that beginning readers can use their knowledge of rhyming words to read words by analogy.

5) By using context cues to predict words: The contexts are the readers' knowledge of the language and the world and their memory of the text already read. However, this does not account for the way that readers read most words in texts. Studies show that on the average, only $25-30 \%$ of the words can be guessed correctly (Stanovich 1980, cited in Ehri 1998).

A large number of studies of reading in L1 have consistently shown that efficient/fluent word-recognition skills play a critical role in successful reading. This efficient/fluent word-recognition skill is also referred to as "automatic" word-recognition skill. Laberge and Samuels' (1974) Automaticity Theory described the development of fluency/ automaticity using three components (Samuels, 1992):

1) decoding,

2) comprehending, and

3) attending.

Decoding and comprehending are the two basic cognitive processes in reading mentioned above. "Attention" refers to "selective attention", i.e., "the ability to focus one's mental energy and effort on certain aspects of the environment and to filter out other part that one does not want to process" (Samuels 1992: 129). Mental energy and effort are needed in cognitive processes such as decoding and comprehending in reading, and there are limits on how much information the human mind can process at one time.

Samuels, Schermer, and Reinking (1992: 131) state that in reading, a beginning reader focuses attention on decoding first, and only later switches attention to comprehending, therefore making beginning reading slow and difficult. Besides, the visual unit that a beginning reader uses in decoding is often as small as a single letter. With practice, the length of the visual unit increases. This model of the shift in attention or focus of a beginning reader is illustrated as follows:

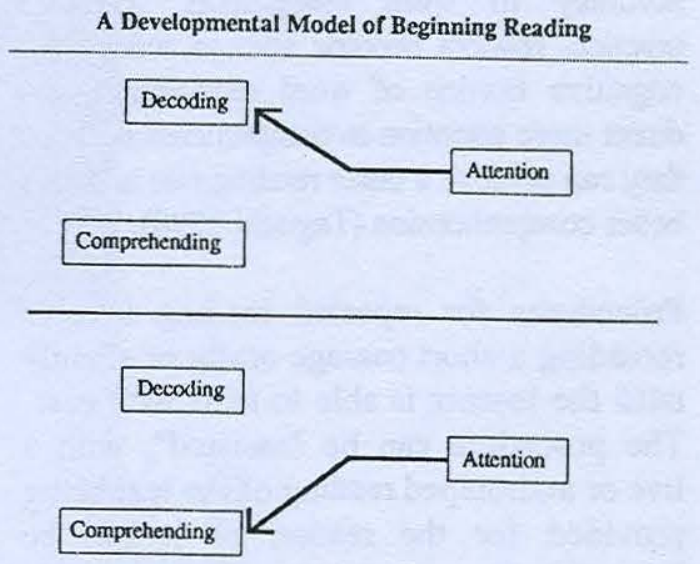

Figure2. A developmental model of beginning reading (Samuels et al. 1992: 131)

As for proficient/fluent readers, they learn to perform both processes in a way that allows their attention to focus on the meaning of the text while the mechanics of deciphering operates "automatically". The visual unit in fluent reading is the whole word. This model of a fluent reader is 
illustrated as follows (Samuels, Schermer, and Reinking 1992: 133):

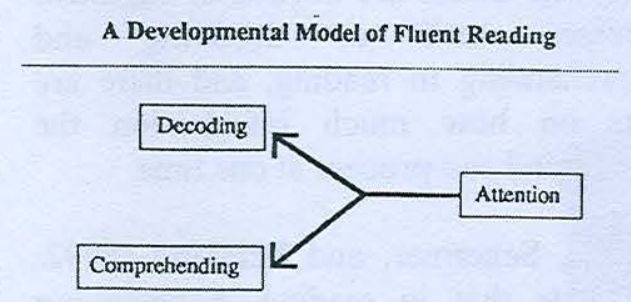

Figure3. A developmental model of fluent reading (Samuels et al. 1992: 133)

\section{How to become a fluent or proficient reader}

Studies and researchers have provided empirical evidence that practice through repeated reading is a primary factor in helping L1 learners develop fluency/automaticity and accuracy in word recognition. Through practice, readers become able to reduce the cognitive burden of word recognition and direct more attention to comprehension. Thus they can achieve a faster reading rate and also better comprehension (Taguchi 1998).

Procedures for repeated reading involve rereading a short passage orally or silently until the learner is able to read with ease. The procedure can be "assisted", with a live or audiotaped reading of the text being provided for the reader, or it can be "unassisted", without an audio reading model of the text being supplied.

Taguchi (1998) studied the effects of repeated readings in $\mathrm{L} 2$ or FL in Japanese learners of English. The study found that repeated readings are as effective in developing the word-recognition skills of FL readers within practiced passages as they are for L1 readers, and that using an audio model of reading passages in the repeated readings in $\mathrm{L} 2$ or FL has some advantages, one being that it provides prosodic features which help learners segment sentences into meaningful units. In addition, the use of an audio reading model in repeated readings can keep learners interested in their reading activity, as opposed to repeated reading without audio models, which has often been argued to cause learners to become bored and unmotivated.

Another issue in the development of reading skills in FL is the issue of the two aspects of reading skills: silent-reading skills and reading-aloud (oral-reading) skills, especially for adult learners.

In Taguchi's (1998) study of repeated readings, the reading procedure used for the repeated readings was silent reading, both with and without audiotaped models of the text. Oral reading was only used once in the final reading to calculate the reading rate in comparison with silent reading. Taguchi made the observation that older, more mature FL/L2 learners rarely read aloud when reading for information or for enjoyment. Therefore, if oral reading is always required in the repeated reading procedure, it might cause them to become less interested or less motivated.

Kailani (1998) observed that the literature on the development of reading skills, in which reading for meaning is central, have placed emphasis on silent reading and deemphasize reading aloud. However, he proposed that both types of reading can be complementary to each o ther in language teaching, i.e., reading aloud is primarily useful as "reading for language" and reading silently is useful as "reading for meaning". 
Kailani acknowledged that in real life we rarely read aloud; however, he suggested that there are certain types of texts that are natural for reading aloud such as songs, lyrics, plays, dialogues, and prose and verse from literature.

Kailani gave various justifications for using oral reading or reading aloud in FL teaching from his observations in teaching Arab learners of English. For example:

- reading aloud systematically trains learners to recognize the visual configuration of words and to associate sound with meaning;

- reading aloud improves pronunciation and oral fluency; and

- reading aloud provides exposure to and practice in the prosody of FL, such as its intonation and rhythm, and thus enhances the comprehension process.

Thus, Kailani suggested that with suitable reading materials corresponding to the learner's level and interests, reading aloud can be integrated into language development as a whole.

Regarding the issue of the association between the sound and visual word recognition in the reading process, one of the characteristics of proficient readers uncovered by Weaver (1998: 210-211) is that proficient readers automatically "hear" the words of the text in their mental ear. This suggests that automatic word recognition includes an automatic association between word form and pronunciation.

To sum up, studies suggest that

- repeated reading is a way to develop automaticity/fluency in word recognition skills in both $\mathrm{L} 1$ and L2;
- for L2, assisted reading, i.e., using an audiotaped model of the reading passage during the repeated readings, has some additional advantages with respect to pronunciation and prosody of L2;

- for $\mathrm{L} 2$, oral reading improves the pronunciation and oral fluency of learners and reinforces the association of the sound, the meaning, and the word form.

\section{Features of karaoke that are relevant in teaching reading skills}

Karaoke is music video with text lyrics on screen. The typical purpose of karaoke is to provide lyrics to sing along with the melody, with the text lyrics corresponding to the melody highlighted as the music progresses. Karaoke also has accompanying vocals to serve as an audio "model" of the sing-along. These accompanying vocals can be muted. The text lyrics on screen can be in transliteration, or in the local script or both. Thus karaoke provides audio, visual, and also textual information at the same time.

We can also view karaoke as songs with visuals and lyrics. Hubbard et al. (1993: 92) listed the following arguments in favor of using songs in language teaching for all age groups, which also can be considered as arguments in favor of karaoke.

- Songs increase motivation to learn a language because, by learning a song, learners feel a sense of achievement

- Songs give learners intensive practice in selected patterns, but without boredom.

- Songs are memorable for learners, as is the language practiced in them.

- Songs can give learners pronunciation practice. 
- Songs can provide learners with insight into FL culture.

- Singing songs is a group activity which helps bring the group together and breaks down the barrier that prevents learners from learning a language effectively.

In addition, some song lyrics make use of poetic devices such as rhyming and repetition (word repetition and sentence structure repetition). Such karaoke lyrics thus provide repetitive examples of the words and grammatical patterns used in a real, meaningful context, and, in the case of rhyming syllables, they also make use of repetitive syllable structure. As mentioned above, Goswami (1998) found that beginning readers can use their knowledge of rhyming words to read words by analogy.

As discussed above, in languages employing a non-Roman alphabetic script with no spaces as word/syllable boundary markings, recognizing word/syllable forms among the strings of letters is a crucial step in the reading process. The text that provides opportunities for repetitive exposure and practice in these patterns thereby enhances the reading skill, which is regarded as an important skill in the $\mathrm{L} 2$ acquisition process.

Other features of karaoke that can enhance the language-learning process, especially in script-reading skill, follow.

- For karaoke with the lyrics shown in L2 script, the highlighted text helps guide the learner's eye to the beginning of the syllable/word, which is helpful for readers, especially in scripts with no space between words, such as Thai. The speed that the highlighting moves along the text also sets the word/syllable reading pace for the learners to follow.
- Karaoke lyrics can be used as a reading practice text in both assisted and unassisted reading. The vocals accompanying the lyrics provide the audio model for reading in an assistedreading practice, or the vocals can be turned off for unassisted-reading practice.

- For oral-reading practice, the learners can compare their pronunciation with the karaoke vocals model, thus helping them practice for accuracy in pronunciation.

- The visual information from karaoke scenes, if corresponding to the text being presented, provides contexts to aid in the understanding of the text whether presented for readingcomprehension activities or listeningcomprehension activities, especially for some cultural concepts that are best understood from visual information. In addition, the accompanying vocals and the lyrics on screen provide mutual help with the reading- and listeningcomprehension activities respectively.

In sum, as a language teaching material, karaoke can be viewed as a short authentic text with the sung vocals functioning as an audio reading model, accompanied by a corresponding visual context.

\section{Shortcomings of karaoke as a language teaching material}

As is the case with any "authentic" language materials whose main purpose is entertainment, not for use as instructional materials, commercially available karaoke has some shortcomings in the following issues concerning its use as an instructional material for non-Roman-script languages: 


\section{Language issues}

\section{Lyrics/text/script/}

In non-Roman-script languages, karaoke lyrics texts can be either in the script of the language or, for international appeal to foreign consumers, "in a Romanized transliteration." The main problem with transliteration is that, as is often the case with n on-Roman-script l anguages, there is no standardized transliteration system, so each karaoke company may use a transliteration that they themselves devise, which is to some degree inconsistent with all others. Another potential problem is that some karaoke songs present text of lyrics only in transliteration, which makes them unusable as instructional materials for script reading.

\section{genres/registers/styles}

Language styles/registers used in lyrics depend on the target audience and the subject matter of the songs. For example, pop songs targeting teenagers tend to include a great deal of trendy colloquial forms and slang. Love songs tend to incorporate more literary words. Country songs tend to use simple language, though they also can be peppered with local dialectal vocabulary items. The types of songs that are made into karaoke may not be appropriate for use as class material to suit the classes' purposes, needs and the language level and skill to be taught.

\section{Content of lyrics and accompanying visuals}

Ideally, karaoke lyrics to be selected for use as language-learning material should be meaningful and coherent, with accompanying visuals that correspond well to, or are relevant to, the content conveyed in the lyrics in order to be helpful as a visual context for the language material. However, commercially available karaoke songs do not always provide visual cues relevant to the songs.

\section{Vocals}

Two important issues for vocals in karaoke that are suitable for use as "reading models" in language instruction are 1) clear pronunciation and 2) slow speed.

Pronunciation: The pronunciation should be clear and not distorted to fit the tune. This is of special importance with prosodic elements of the pronunciation that can be distorted by the tune, such as stress patterns and tones. ${ }^{7}$

Speed: The speed of the music and vocals should be slow.

However, a majority of commercially available karaoke, especially pop songs, do not always pay attention to the issue of clear pronunciation. Some pronunciations are even deliberately distorted to add color to the vocals. Certain types of rhythms in karaoke pop songs that are naturally fast can thus be unusable as languageinstruction materials for beginners.

${ }^{7}$ For Thai, Deepuengton (1982) concluded that, in Thai country songs, tone distortion may occur in pitch height and pitch contour, with the Thai "mid level" tone having a greater tendency to be distorted. The perception of distorted tones in Thai is conditioned more by the contour shape of the tone than the pitch height. However, with contextual clues, native Thai speakers can perceive the distorted tone correctly at a high percentage. 
Using karaoke features in the "Learning to Read Thai from Songs" project

As discussed above, karaoke has many desirable features and thus has good potential for use as language-teaching material, especially for reading skill. The shortcomings mentioned are prevalent only in commercial karaoke, which is not intended for language instruction. Those shortcomings can easily be avoided in karaoke-type material that is developed for use a s instructional material for language teaching and incorporates only the desirable features of karaoke.

The "Learning to read Thai from songs" project aims to develop such materials. This project aims to enhance the instruction of reading skills in beginning-level Thai courses. The target audience is students who already know all of the Thai alphabet and writing system and some basic, conversational Thai. Thai script-reading and -recognition practice, in addition to other language-skills practice, such as pronunciation practice and structural drills, are achieved by using a multimedia presentation of the lyrics and sung vocals of Thai songs, accompanied by corresponding animations, that is accessible via the web. The project website address is:

\section{http://www.hawaii.edu/thai/thaisongs}

The presentation of each song in this project consists of:

- background information about the song, such as the history, the subject matter referred to, the lyricist and the composer, if known;
- text lyrics in Thai script, with syllable/word boundaries marked by space;

- audio of pronunciation/reading linked to the text lyrics, by word and by verse;

- English explanation of some vocabulary items;

- English translation of lyrics, verse by verse;

- grammar notes;

- culture notes; and

- sung vocals.

The sung vocal is presented in two ways:

1. as an audio file of the whole song; and

2. as a "karaoke" style sing-along, i.e., the words of the lyrics are each highlighted as that particular word is sung, accompanied by animation corresponding to the meaning of each verse; the user can choose to play either by a single verse or the entire song and can play either repeatedly.

The sung vocals are performed by a professional singer and musician ${ }^{8}$ for clarity of pronunciation and control of the pace and speed of the sung songs.

Seven songs were selected for this project. The criteria for selection are:

1) language features, such as vocabulary items and sentence structures, that are appropriate for beginning learners of Thai; and

2) commonly known songs that are royalty-/copyright-free, such as children's

\footnotetext{
${ }^{8}$ The vocals and music for this project were performed by Mr. Torpong Wannawati, Faculty of Education, Chiangmai University (editwnnw@chiangmai.ac.th).
} 
songs, traditional folksongs, and special occasion songs.

The seven songs included in the project are:

\section{1. ช้าง 'Elephant'}

2. สุขาอยู่หนใด 'Where is the Bathroom?'

3. ผู้ใหญ่ลี 'Village Chief Lee'

4. ตาอินกะตานา 'Old Man In and Old Man $\mathrm{Na}$ '

5. งามแสงเดือน 'Beautiful Moonlight'

6. ใกล้เข้ามาอีกนิด 'Come a Little Closer'

7. ตามองตา 'Our Eyes Meet'
Figures $4 \mathrm{a}$ and $4 \mathrm{~b}$ are screen shots from the display page of the song "Elephant" showing the presentation format of a song in this project. Figure 5 is a screen shot of a karaoke sing-along display of the "Elephant" song using the play-by-verse option. The word being sung is งวง 'trunk' which is highlighted. The animation shows an arrow pointing to the "trunk" of the elephant.

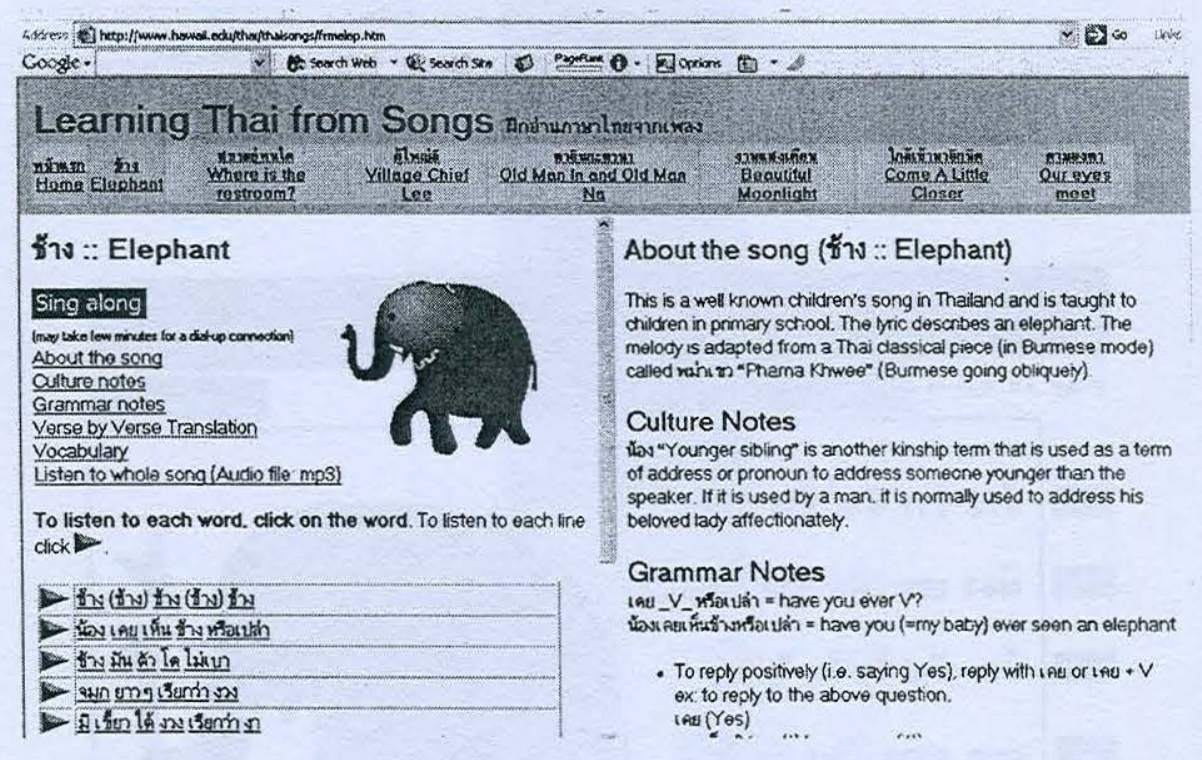

Figure 4a. A sample screen shot from the song "Elephant" 


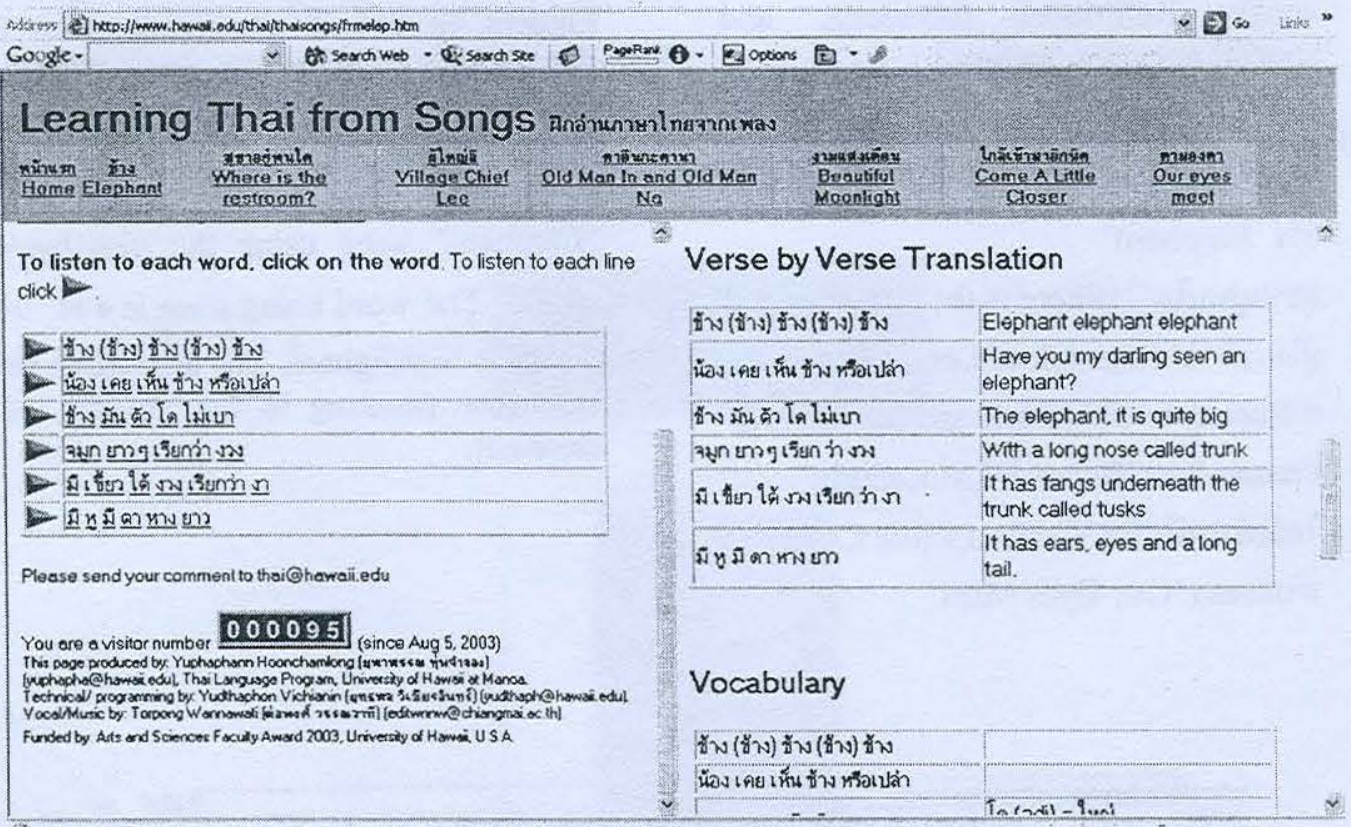

Figure $4 \mathrm{~b}$. A sample screen shot from the song "Elephant"

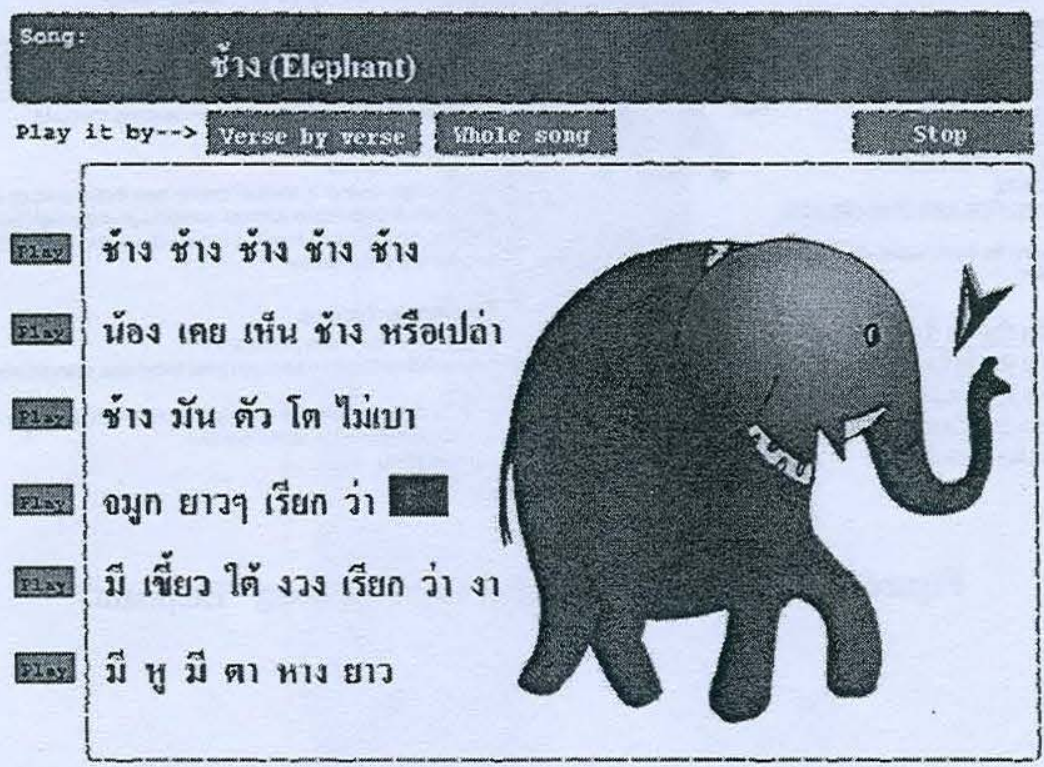

Figure 5. A sample screen shot from the karaoke presentation of the "Elephant" song 


\section{The design and implementation of a karaoke sing-along page}

In incorporating the desirable features of karaoke into each sing-along multimedia web page, the display page is designed to have the following elements:

- animation from still images; synchronization of the animation with the sung vocals;

- correct display of the lyrics in Thai script that is viewable on a computer using any platform;

- display of English glosses of selected words in the lyrics;

- synchronization of the highlighting of the written words in the lyrics with the words being sung; and

- a trigger to start and stop repeated play of the sung vocals and the highlight of lyrics for a verse at a time or continuously for the whole song.

We chose to use Macromedia Flash MX software to meet the technical requirements outlined above. Flash MX is an animationcreation program for the web that has a timeline feature allowing for the timealigned synchronization of the actions of graphics, audio, and text objects.

The Thai text lyrics on each karaoke singalong page are recreated as a graphic object (.gif file) in order to control the correct display of the Thai font and to interact and synchronize with other objects, namely the corresponding sound file and the highlight color.

Figure 6 shows a sample timeline structure and figure 7 shows a sample of the Flash action scripts used for each object.

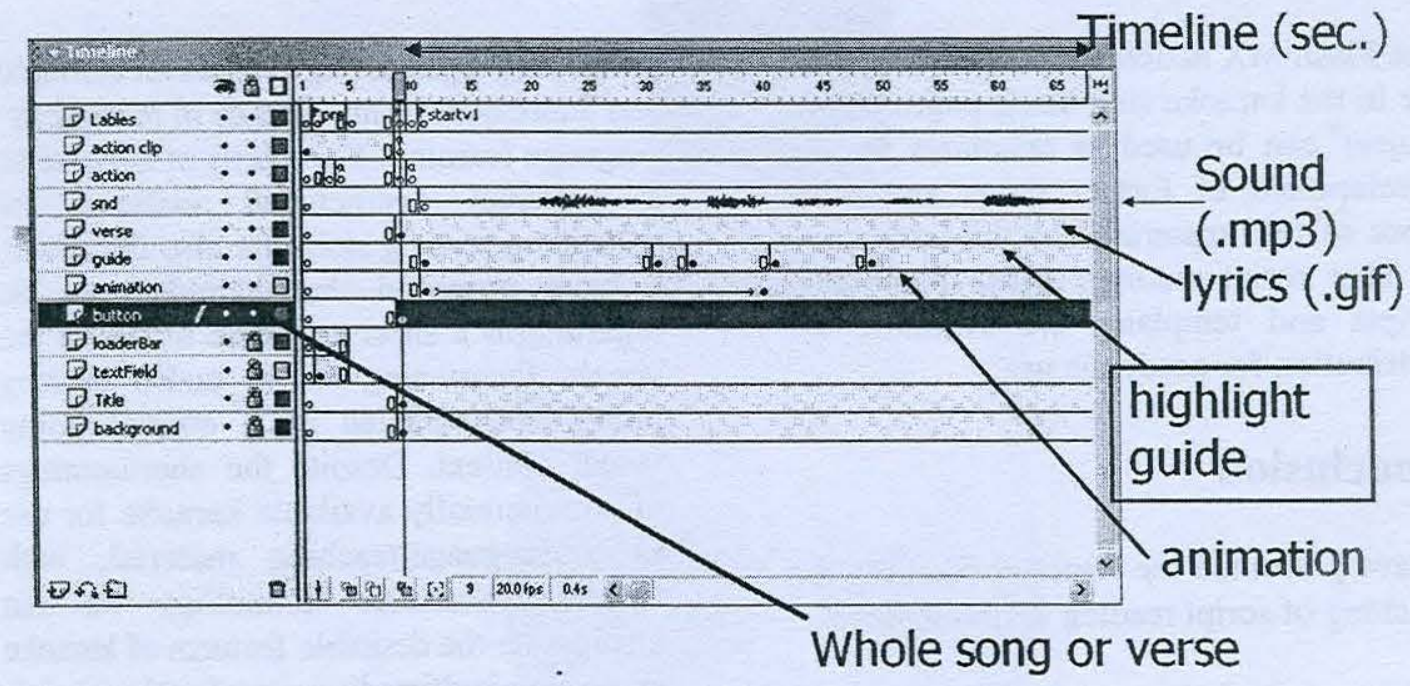

Figure 6. Timeline and synchronization for actions for each object 


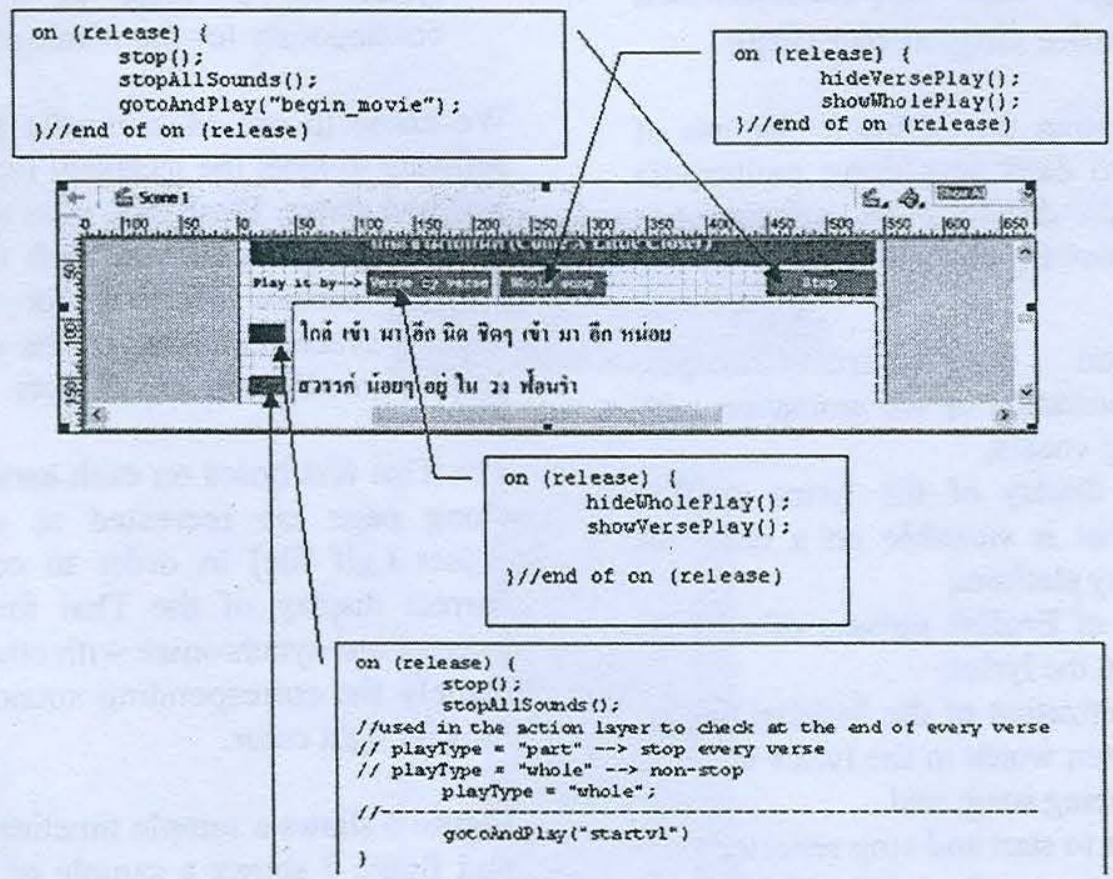

Figure 7. A sample of Flash action scripts

The Flash MX action scripts developed for use in the karaoke sing-along pages of this project ${ }^{9}$ can be used as templates for the development of further songs and other types of text materials for the instruction of Thai script reading. These Flash MX scripts and templates are available for distribution for academic use.

\section{Conclusion}

I have presented the issues concerning the teaching of script reading in non-Roman-

\footnotetext{
${ }^{9}$ Flash MX action scripts for this project were written by Mr. Yudthaphon Vichianin, Communication and Information Sciences Program, University of Hawai'i-Manoa (yudthaph@hawaii.edu).
}

script languages, using Thai as an example, and addressed the importance of reading in language learning. The merits of karaoke as a potential instructional material for enhancing reading skills are also discussed. I have proposed that karaoke can be regarded as a short authentic text with the vocals functioning as an audio reading model accompanied by a corresponding visual context. Despite the shortcomings of commercially available karaoke for use as a language-teaching material, with currently available technology we can incorporate the desirable features of karaoke in creating multimedia instructional materials for language instruction and learning, as shown by a project such as "Learning to Read Thai from Songs", which can be viewed at the website:

http://www.hawaii.edu/thai/thaisongs 


\section{References}

Brown, J. 1979. AUA Language Center Thai course reading and writing text: Mostly reading. Bangkok, Thailand: AUA Language Center.

Danvivathana. 1987. The Thai writing system. Hamburg, Germany: Helmut Buske Verlag.

Deepuengton. 1982. Distortion of tones in Thai country songs. Unpublished master's thesis, Chulalongkorn University, Bangkok, Thailand.

Dornic, S. (Ed.). 1977. Attention and performance. New York: Academic Press.

Ehri, L. 1998. Grapheme-phoneme knowledge is essential for learning to read words in English. In J. L. Metsala \& L. Ehri (eds.), Word recognition in beginning literacy. London: Lawrence Erlbaum Associates.

Goswami, U. 1990. “A special link between rhyming skill and the use of orthographic analogies by beginning readers" in Journal of Child Psychology and Psychiatry, 31.

Goswami, U. (1998). "The role of analogies in the development of word recognition." In J. L. Metsala \& L. Ehri (eds.), Word recognition in beginning literacy. London: Lawrence Erlbaum Associates.

Haas, Mary. 1964. Thai-English student's dictionary. Stanford, CA: Stanford University Press.

Henderson, L. (Ed.). 1984a. Orthographies and reading. London: Lawrence Erlbaum Associates.

Henderson, L. 1984b. Writing systems and reading processes. In L. Henderson (ed.), Orthographies and reading (pp. 11-24). London: Lawrence Erlbaum Associates.
Hubbard, P., Jones, H., Thornton, B., \& Wheeler, R. 1993. A training course for EFL (11 ${ }^{\text {th }}$ impression). Oxford, England: Oxford University Press.

Kailani, T. 1998. Reading aloud in EFL revisited. Reading in a Foreign Language, 12 (1).

Krashen, S. 1993. The power of reading: Insights from the research. Engelwood, CO: Libraries Unlimited.

Laberge, D., \& Samuels, S. J. 1974.

Towards a theory of automatic information processing in reading. Cognitive Psychology, 6.

Metsala, J. L., \& Ehri, L. (Eds.). 1998. Word recognition in beginning literacy. London: Lawrence Erlbaum Associates.

Rumelhart, D. 1977. Toward an interactive model of reading. In S. Dornic (ed.), Attention and performance (Vol 6). New York: Academic Press.

Samuels, S. J., \& Farstrup, A. E. (eds.). 1992. What research has to say about reading instruction. Newark, DE: Intemational Reading Association.

Samuels, S. J., Schermer, N., \& Reinking, D. 1992. "Reading fluency: Techniques for making decoding automatic". In S. J. Samuels \& A. E. Farstrup (eds.), What research has to say about reading instruction. Newark, DE: International Reading Association.

Stanovich, K. 1980. "Towards an Interactive - compensatory model of individual differences in the development of reading fluency". Reading Research Quarterly, 16.

Taguchi, E. 1998. "The effects of repeated readings on the development of lower identification skills of $\mathrm{FL}^{\circ}$ readers." Reading in a Foreign Language, 11 (1). 
Tomlinson, B. 2000. "Beginning to read forever: A position paper." Reading in a Foreign language 13(1).

Weaver, C. 1994. Reading process and practice $\left(2^{\text {nd }}\right.$ ed.). Portmouth, $\mathrm{NH}$ : Heinemann. 